\title{
COGNITIVE CHANGES IN PREVIOUSLY UNTREATED HYPERTENSIVE PATIENTS AFTER SIX MONTHS OF TREATMENT WITH LERCANIDIPINE
}

\author{
Zlatkova V., *I. Dimitrov, Zh. Georgieva \\ Clinic of Internal Medicine, *First Clinic of Neurology, \\ "Sveta Marina" University hospital, Varna, Bulgaria
}

Reviewed by: assoc. prof. At. Penev

\section{SUMMARY}

The relationship between arterial hypertension and cognitive disturbances is well established. Elevated blood pressure in middle age is known to predict cognitive impairment in advanced age. Early and aggressive control of blood pressure should therefore reduce the risk of later cognitive decline. We performed a study assessing the efficacy of lercanidipine, a vasoselective dihydropyridine calcium antagonist, on blood pressure and cognitive functions in previously untreated hypertensive patients. Good control of blood pressure as well as improvement of memory and attention was achieved after 6 months of treatment.

Key words: arterial hypertension, cognitive impairment, lercanidipine

\section{INTRODUCTION}

Medical and social significance of cognitive disturbances and dementias has been growing constantly in the last decade. Multiple risk factors for cognitive decline and dementia have been identified (8). The role of vascular factors is considered to be significant (9). It is widely discussed in the literature, and current studies affirm that vascular factors such as arterial hypertension $(\mathrm{AH})$ could increase the risk not only for vascular cognitive impairment, but also for Alzheimer's disease (2).

In most countries of the European Union Alzheimer's disease is the most frequent subtype of dementia, followed by vascular dementia (7). In Central and Eastern European countries like Poland and the Russian Federation though, as well as in some Asian countries like Japan, vascular dementia is the leading subtype $(4,5)$. Bulgaria seems to be in the middle, as the single study of dementia prevalence performed in the country shows that Alzheimer's disease is the most frequent but vascular and mixed dementia follow closely (1).

The relationship between arterial hypertension and cognitive disturbances is well established. Elevated blood pressure in middle age is known to predict cognitive impairment in advanced age. On the other hand, early and aggressive control of blood pressure reduces the risk of later cognitive decline (11). The number of studies of cognitive

Address for correspondence:

V. Zlatkova, Clinic of Internal Medicine

"Sveta Marina" University hospital, Varna, Bulgaria

e-mail:dr_zlateva@mail.bg functions before and after treatment with blood pressure lowering drugs may still be insufficient, but the beneficial effect of calcium channel blockers on cerebrovascular disease is confirmed (3).

The aim of the present study was to assess cognitive status and efficacy of lercanidipine, a vasoselective dihydropyridine calcium antagonist, on blood pressure and cognitive impairment after 6 months of treatment in previously untreated hypertensive patients.

\section{PATIENTS AND METHODS}

Thirty-six patients aged $54 \pm 2$ years, with untreated $\mathrm{AH}$ were included in the study. Treatment with 1 tablet $(10 \mathrm{mg})$ of lercanidipine daily was started. One tablet $(25 \mathrm{mg})$ of the diuretic hydrochlorothiazide was added in patients with insufficient control of blood pressure. Neuropsychological assessment of memory, attention, thinking and intelligence was performed twice for all participants. Baseline assessment was done right before initiation of treatment, and tests were repeated 6 months afterwards.

\section{RESULTS}

Treatment with lercanidipine led to good control of $\mathrm{AH}$, achieving mean values of systolic blood pressure of $135 \pm 4$ $\mathrm{mmHg}$, and of diastolic blood pressure equal to $87 \pm 6$ $\mathrm{mmHg}$.

In 21 out of 36 hypertensive patients (77\%) hypoprosexia of active attention and mild impairment of fixation memory 
were found before treatment, while thinking and intelligence were spared. Following 6 months of treatment, improvement of cognition was noted: better results were obtained for retention and fixation memory, as well as for attention span.

\section{DISCUSSION}

The results of our study showing the presence of cognitive impairment in untreated hypertensive patients are in line with literature data reporting that high diastolic blood pressure at baseline predicts later impaired cognitive performance. In another study an increment of $10 \mathrm{~mm} \mathrm{Hg}$ in DBP was associated with $7 \%$ higher odds of cognitive impairment (10). These data should be discussed mainly in cases with longer duration of $\mathrm{AH}$ when the presence of asymptomatic and latent forms of cerebrovascular disease is more likely (6).

Hypertension can lead to damage to the endothelium of the cerebral arteries which can disrupt the blood-brain barrier, thus allowing the entry of toxic substances to the brain. Atherosclerosis in the larger arteries and blockages of the smaller arterioles can lead to disease of the white matter (12). The impairment of cerebral blood flow in these conditions suppresses brain metabolism and underlies the development of cognitive deficit.

Among the most easily impaired cognitive functions in subclinical insufficiency of cerebral blood flow are notably active attention, concentration and fixation memory. According to our results, they may be impaired in untreated hypertensive patients. We should emphasize on the fact that good control of blood pressure achieved after 6 months of treatment with lercanidipine is followed by improvement of these functions.

\section{CONCLUSION}

In untreated hypertensive patients in our study lercanidipine not only achieved good control of blood pressure, but also improved cognitive functions. These beneficial effects should be taken into consideration when decisions are made about administering the right medication in cases of arterial hypertension.

\section{REFERENCES}

1. Димитров, И. Проучване на деменциите и леките когнитивни нарушения сред населението на град Варна. Дисертация за присъждане на образователна и научна степен "Доктор". Варна, 2009.

2. Breteler, M.M. Vascular risk factors for Alzheimer's disease: an epidemiologic perspective Neurobiol Aging 2000, 21, 153-160.

3. Dalal, P.M., Dalal, K.P. Use of calcium channel blockers in acute ischemic cerebrovascular disease $J$ Assoc Physicians India 1995, 43, 394-397.

4. Gabryelewicz, T. The prevalence of dementia in the population of the Warsaw district of Mokotow from 65 to 84 years of age Psychiatr Pol 1999, 33, 353-366.

5. Jorm, A.F. Cross-national comparisons of the occurrence of Alzheimer's and vascular dementias Eur Arch Psychiatry Clin Neurosci 1991, 240, 218-222.

6. Kilander, L., Nyman, H., Boberg, M., Hansson, L., Lithe11, H. Hypertension is related to cognitive impairment: a 20-year follow-up of 999 men Hypertension 1998, 31, 780-786.

7. Lobo, A., Launer, L.J., Fratiglioni, L., Andersen, K., Di Carlo, A., Breteler, M.M., Copeland, J.R., Dartigues, J.F., Jagger, C., Martinez-Lage, J., Soininen, H., Hofman, A. Prevalence of dementia and major subtypes in $\mathrm{Eu}-$ rope: A collaborative study of population-based cohorts. Neurologic Diseases in the Elderly Research Group Neurology 2000, 54, S4-S9.

8. Prince, M., Cullen, M., Mann, A. Risk factors for Alzheimer's disease and dementia: a case-control study based on the MRC elderly hypertension trial Neurology 1994, 44, 97-104.

9. Solfrizzi, V., Panza, F., Colacicco, A.M., D'Introno, A., Capurso, C., Torres, F., Grigoletto, F., Maggi, S., Del Parigi, A., Reiman, E.M., Caselli, R.J., Scafato, E., Farchi, G., Capurso, A. Vascular risk factors, incidence of $\mathrm{MCI}$, and rates of progression to dementia Neurology 2004, 63, 1882-1891.

10. Tsivgoulis, G., Alexandrov, A.V., Wadley, V.G., Unverzagt, F.W., Go, R.C., Moy, C.S., Kissela, B., Howard, G. Association of higher diastolic blood pressure levels with cognitive impairment Neurology 2009, 73, 589-595.

11. Tzourio, C., Anderson, C., Chapman, N., Woodward, M., Neal, B., MacMahon, S., Chalmers, J. Effects of blood pressure lowering with perindopril and indapamide therapy on dementia and cognitive decline in patients with cerebrovascular disease Arch Intern Med 2003, 163, 1069-1075.

12. Waldstein, S. The relation of hypertension to cognitive function Current Directions in Psychological Science 2003, 12, 9-13. 